\title{
E1 Barranco de los Molinos y las Huertas Mayores en Ibi (Alicante). Paisajes hidráulicos a proteger
}

\author{
Ágata Marquiegui Soloaga y José Lajara Martínez \\ patrimoniohidraulico@gmail.com, joselajara5@gmail.com
}

\begin{abstract}
Resumen: El barranco de los Molinos y las Huertas Mayores de Ibi albergan uno de los conjuntos hidráulicos más relevantes de la provincia de Alicante. Numerosos yacimientos de todas las épocas certifican que el lugar ha estado ocupado por diversos grupos culturales. En un espacio relativamente reducido de aproximadamente 3,5 kilómetros cuadrados se puede estudiar cómo se establecen distintos asentamientos en torno al recurso del agua a lo largo de la historia. Futuras prospecciones y excavaciones arqueológicas podrían dar luz sobre nuevas estructuras hidráulicas. Secularmente el caudal de la fuente de Santa María se ha empleado para el riego de la huerta, para abastecimiento de la población y para mover ocho molinos. Hoy el agua fluye por medio de una galería y corre por una acequia que va tallada en la roca y que toma altura en cada tramo para mover los molinos. Los elementos patrimoniales que se estudian, como yacimientos, estructuras hidráulicas, arquitectura y paisaje de la huerta, caminos históricos y ąagadores, definen unos entornos paisajísticos diferenciados también por las visuales: el Entorno del Barranco de los Molinos, que esencialmente es la cuenca receptora del caudal, y el Entorno de las Huertas Mayores, que es el perímetro del espacio regado.
\end{abstract}

Palabras clave: Yacimientos, estructuras hidráulicas, riegos, molinos, huerta, paisaje.

\begin{abstract}
The Barranco de los Molinos and Huertas Mayores of Ibi host one of the most important hydraulic sets of the province of Alicante. Numerous archaeological site of all ages certify that the place has been occupied by various cultural groups. In a relatively small space, approximately 3.5 square kilometers, it is possible to study how different settlements were established around the water resource throughout history. Future surveys and excavations could shed light on new hydraulic structures. Secularly flow from the font of Santa María has been used for watering the garden, supply people and move eight mills. Today, water flows through a gallery and runs through a canal which cuts into the rock and takes altitude to move the mills. The heritage elements that are studied, such as reservoirs, hydraulic structures, architecture and landscape gardening, and historic roads, define a differentiated landscape environments also visual: The Environment of the Barranco de los Molinos, which is essentially the recipient basin flow, and the environment of Huertas Mayores, which is the perimeter of the irrigated area.
\end{abstract}

Keywords: Archaeological sites, hydraulic structures, irrigation, mills, garden, landscape.

\section{Introducción}

El Barranco de los Molinos y las Huertas Mayores se sitúan al norte de la población de Ibi en Alicante. El cauce avena la sierra del Menejador y su cuenca la integran los afluentes de Santa María, La Camarera, L'Horteta Vella y del Sixto. Cerca de la población se le unen por la izquierda el riuet de les Caixes, con sus afluentes el barranco dels Cirers, el de les Raboses, Foia de la Fábrica y Foiaderes. El cauce presenta un régimen con marcada irregularidad con caudales discontinuos y normalmente nulos sobre todo en verano. La sierra se compone de formaciones de calizas eocenas en las que la acción kárstica facilita la filtración del agua y su reaparición en varias surgencias y manantiales. La fuente principal es la llamada de Santa María. En torno al recurso del agua se han establecido desde antiguo distintas culturas y esto se refleja en los numerosos yacimientos arqueológicos existentes. 
Un sendero recorre el curso a la sombra de la vegetación de ribera en la que abundan chopos y olmos. Comienza encajado entre laderas de caliza cubiertas por grupos de bosque típico mediterráneo con pinos y encinas, y se abre en su recorrido al parque natural de la Font Roja y a varias rutas como la del Carrascar de la Font Roja en la que se encuentran varios pozos de nieve. Llegó a haber siete pozos en la sierra que el municipio comparte con Alcoy. El comercio de la nieve tuvo una importancia relevante en la zona desde finales del siglo XVII y principalmente durante los siglos XVIII y XIX (Vicedo y Ramírez, 2004.).

En el mismo se localiza uno de los conjuntos hidráulicos más destacables de la provincia de Alicante. Obras antiguas y modernas han convivido hasta época reciente para regar las Huertas Mayores de Ibi, para abastecimiento de la población y para mover ocho molinos. El agua corre por una acequia tallada en la roca que en cada tramo va manteniendo altura para llenar los cubos de los molinos harineros, y antaño mover las ruedas de batanes y de un molino de papel.

El estudio y la localización de todos los elementos patrimoniales e históricos que integran el barranco y las huertas: yacimientos, estructuras hidráulicas, el sistema de riego, los molinos, la huerta y la arquitectura tradicional, definen dos perímetros paisajísticos claros que hemos denominado como sigue: Entorno paisajístico del Barranco de los Molinos y Entorno paisajístico de las Huertas Mayores. Ambos tienen como telón de fondo una tercera zona asociada al Parque Natural del Carrascal de la Font Roja que hemos determinado como Área de protección forestal y paisajística.

\section{Yacimientos arqueológicos}

La mayor densidad de yacimientos arqueológicos del término de Ibi se localiza en el Barranco de los Molinos y en su entorno. La ubicación y las características de los mismos se conocen por prospecciones y por alguna excavación, pero hoy en día su estudio no deja de ser parcial. Nuevas investigaciones darían luz a muchas incógnitas.

Varios factores promovieron la ocupación de este espacio. El principal es el aprovechamiento de los recursos naturales, hídricos y forestales, a lo que hay que añadir la calidad de las tierras para el cultivo. El curso ha sido siempre una vía natural de comunicación ya que es zona de paso de vías pecuarias, o azagadores, y de antiguas rutas de conexión hacia el norte dirigidas desde la Foia de Castalla hacia el Valle de Polop, Bocairente y Valencia, y del corredor este oeste, que discurría por Villena y Alcoy procedente de Castilla.

La ocupación humana del lugar se remonta desde al menos la Prehistoria Reciente y no se interrumpe hasta nuestros días. Tenemos evidencias del uso funerario en la Cova Despartidor y pinturas rupestres en el Abrigo I de la ladera este del barranco, que se interpretaron como propias del Arte Esquemático (V milenio-II milenio a. C.) (García Atiénzar, 2007). En el Abrigo II se encontraron restos cerámicos realizados a mano. Es destacable por su carácter excepcional la existencia de varias canteras de molinos de mano con innumerables piezas aún insertas en la roca a medio tallar (Anderson y otros, 2003; Anderson, 2011; Lajara y Marquiegui, 2014a; Marquiegui y Lajara, 2014b).

A finales del III milenio a. C. se produce un progresivo desplazamiento de los poblados en el llano hacia los cerros y las laderas de las montañas cercanas, que gozan de una posición 
estratégica para el control visual del territorio. Los asentamientos que dominan son Santa María y La Cascada en la parte oriental del barranco, y el Castell Vell, que está situado en la entrada del mismo. Posteriormente, este último servirá como atalaya en época islámica. En Fernova y San Miguel hubo dos poblados de la Edad del Bronce que ocupan parte de las laderas meridionales de dos cerros de la Serra Grossa. Ambos contralaban la principal vía de comunicación de la Foia de Castalla, conocida como el corredor de La Torre-La Canal.

Los yacimientos de época ibérica y romana se concentran en una franja de terreno de piedemonte, cerca del barranco aguas abajo de los anteriores. Son establecimientos rurales dedicados a la explotación agropecuaria. Se han podido documentar los yacimientos del Camino de la Ermita de San Miguel entre los siglos II-I a. C. y de Les Hortes Sur entre el II a. C. - II d. C. y V d. C. Este último muestra indicios de haber sido una gran propiedad rural, o fundus, de la que dependerían otros asentamientos de menor tamaño como Les Hortes-Norte y L'Horta del Pont-Sur. Las excavaciones recientes descubrieron un complejo de torcularium, lagar o almazara (Lajara y Pérez, 2006; Lajara, 2006.). El yacimiento de Fernoveta tiene material cerámico abundante de varios periodos que ocupa un área amplia. Comprende varias épocas: ibérica (siglos IV a. C. - III a. C.), romana altoimperial y medieval islámica (siglo XI).

En época islámica pequeñas alquerías se distribuían por los bordes de las tierras irrigadas actuales. Su ubicación coincide con muchos de los yacimientos de época ibérica y romana. Gracias a los documentos escritos en época medieval cristiana conocemos el nombre de dos de estas alquerías: Bonetabib y Benetavulea ${ }^{1}$. El yacimiento de la alquería de Altet de Campos está datado entre los siglos XI y XII. Es el mejor conocido de esta época ya que se cuenta con bastante material arqueológico procedente de la excavación realizada en los años 30. Recientemente se excavó parte de la maqbara de L' Horta del Pont de los siglos XII-XIII d. C., que era la necrópolis de la alquería homónima. La comunidad islámica de Ibi construyó dos castillos o atalayas de defensa: el Castell Vell, de adscripción Almohade, de los siglos XII y XIII, construido sobre restos de un asentamiento del Bronce, y el Castell Vermell, de datación medieval islámica y cristiana, que se ubica sobre el cerro de Santa Lucía. En las inmediaciones de la ermita aún se conserva el aljibe construido en época medieval cristiana (Lajara, 2009 y 2011) ${ }^{2}$.

Ibi, junto con Castalla, Onil y Tibi (que conforman la Hoya de Castalla), fue zona fronteriza entre los reinos de Castilla y Aragón en los tiempos de la conquista de Jaime I. Muy cerca discurría la línea de división que trazó con su yerno, Alfonso X el Sabio, en el Pacto de Almizra, de 1244. El castillo de Ibi pertenecía a Ceit Abu Ceyt, gobernador de Valencia descendiente de almohades, que fue aliado de Jaime I y se convirtió al cristianismo hacia 1236, y que en distintas fechas donó el lugar de Ibi junto con otras pertenencias a diversos señores beneficiados tras la reconquista. Desde entonces la posesión de Ibi fue intermitente y confusa ya que cambió de manos en numerosas ocasiones. En esta etapa histórica y en época moderna el casco antiguo de Ibi se convierte en el emplazamiento estable de la población.

\footnotetext{
${ }^{1}$ En una donación de Zeit Abu Zeit a Eximén Pereç de Artieda de mayo de 1251 se citaba la existencia de dos alquerías llamadas Benetabib y Benetauela. ACA, Cancillería, Pergaminos, Jaime I, Serie general, 1252; Chabás, 1995 [1891], V: 301-302; Azuar, 1989: 165, 169, 171; Torró y Nebot, 2007.

2 Véase: Catálogo de yacimientos arqueológicos de la Dirección General de Patrimonio Cultural, Consellería de Turismo, Cultura y Deportes de la Comunidad Valenciana, www.cult.gva.es; Cerdá Bordera, 1983; Segura y Torró, 1985: 26, 41; Azuar, 1989: 165-172; Lajara, 2006 y 2010.
} 

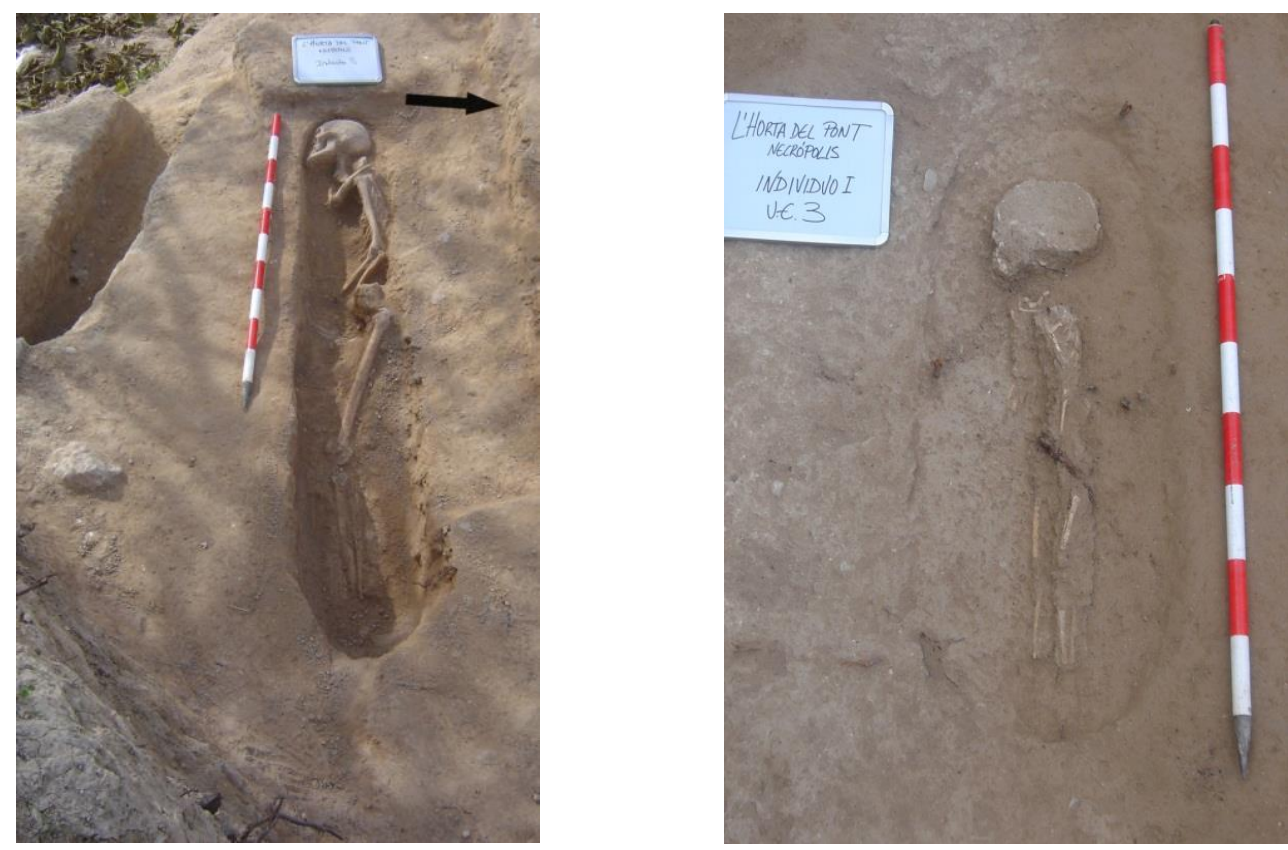

Fig. 1. Dos individuos, uno adulto y otro infantil, hallados en la excavación arqueológica de L’Horta del Pont.

\section{Estructuras hidráulicas}

El agua es el componente primordial que estructura el sistema sobre el que se insertan y se combinan todos los bienes y espacios etnológicos del Entorno del Barranco de los Molinos y de las Huertas Mayores. Los elementos que lo integran se pueden considerar como obras independientes, pero siempre vinculados a esta configuración. Las principales estructuras son la Conducción de aguas potables y el Sistema de Riegos de las Huertas Mayores. Destacan algunas obras que forman parte de las mismas como los molinos, el depósito de aguas potables y el conjunto compuesto por el Molino de Papel, el Lavadero de Arriba y la Balsa de los Regantes. También son reseñables los acueductos, balsas, acequias, partidores y alcavones.

\subsection{Conducciones de aguas potables}

La Fuente de Santa María se encuentra en la cabecera del barranco de los Molinos y a ella se suman diversas fuentes de la zona que afloran con pequeños alcavones o galerías. En su origen la fuente daba lugar a un embalse subterráneo conocido en los documentos como pantanet. La escasez de caudal y el aumento de la demanda supusieron el descenso progresivo del nivel freático y la construcción de perforaciones cada vez a mayor profundidad. La búsqueda y mejora de los caudales para abastecimiento ha sido un empeño constante en la historia de la población. Las primeras prospecciones documentadas son de 1581 cuando un zahorí realizó un sondeo para localizar manantiales. Pocos años antes, en 1578 Ibi había obtenido la declaración de Universidad tras el pago de 6.000 sueldos a la corona (Castelló y Candela, 2001; Verdú i Guillem, 1995). 


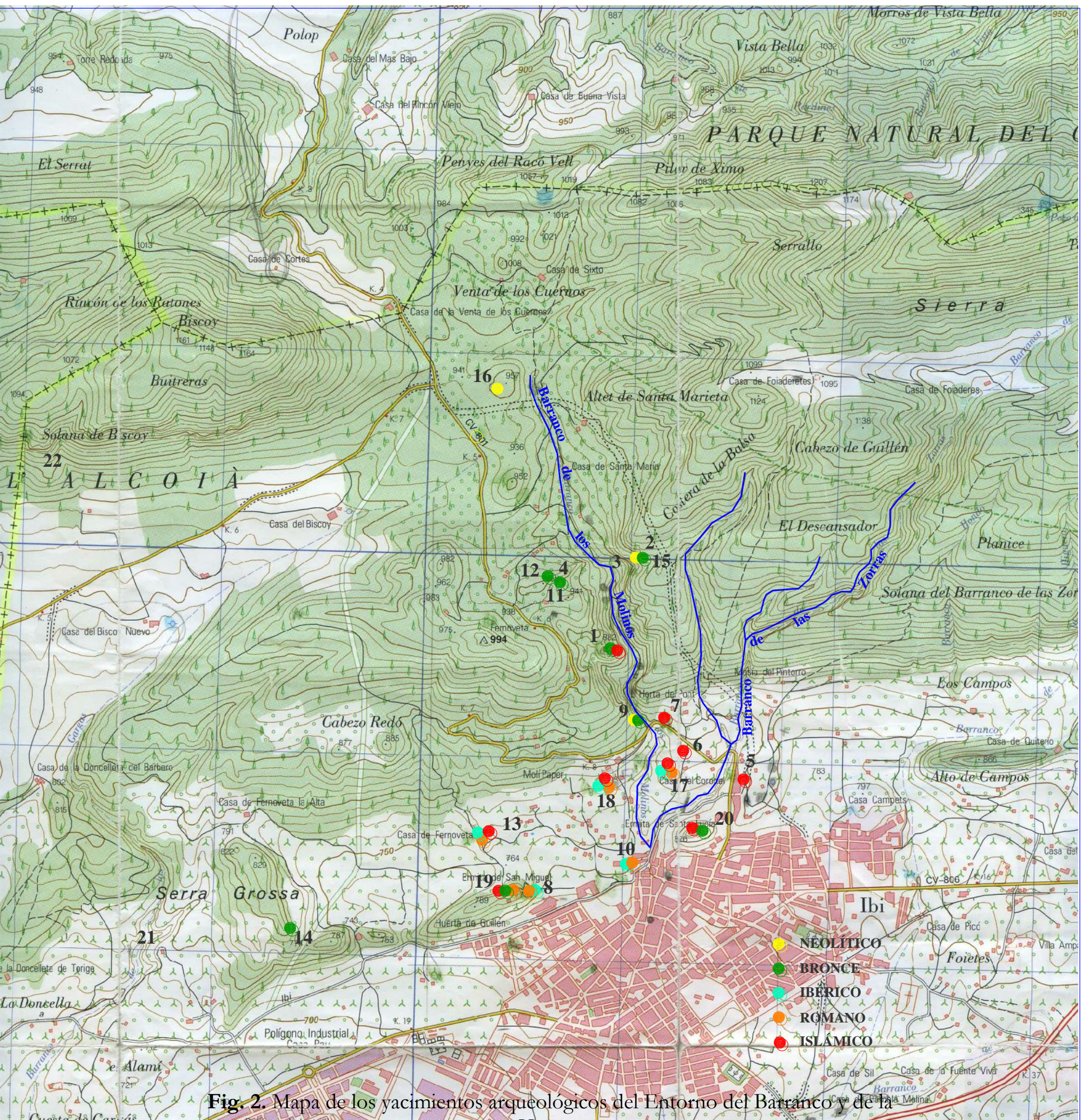

Cuesta dè Gar ás

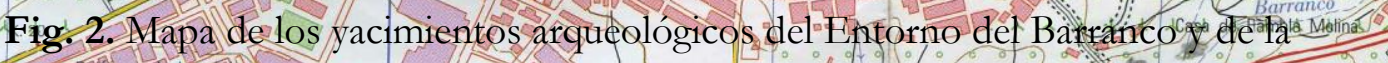

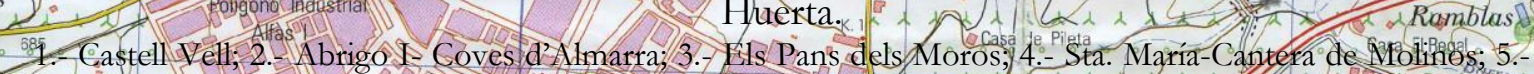

${ }^{68}$ Altet de Campos; 6. L'Horta del Pont-Necropolis; 7. L'Horta del Pồnt Nonte; 8. Camino déla Ermita de San

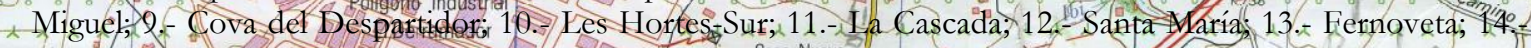

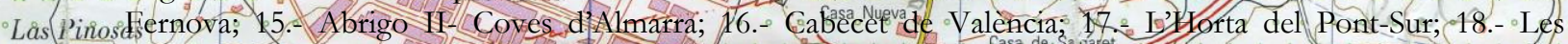
Hortes-Norte, 19-San Mrguel.

El Lloch de Ibi pertenecía a Jijona desde 1420. Había entonces en torno a dieciséis familias, pero la población decreció a finales de siglo por diversos avatares como sequías, epidemias y peste, y en 1490 no quedaban más de tres o cuatro casas. El resurgimiento de la población 
vino de la mano de los exiliados de Jijona que recalaron en el lugar tras la derrota de la Guerra de las Germanías (1519-1523). En 1526 se desplazaron unas cincuenta familias y en 1535 se contaban cincuenta y dos fuegos en Ibi. Los nuevos pobladores impulsaron la creación de una comunidad propia independiente de Jijona, que concluyó con la concesión de Felipe IV del privilegio de Villa Real en 1629. Estos prohombres que provenían de una clase social acomodada ocuparon cargos de relevancia en el municipio -de jurat, justicia, llochtinent de justicia, baile, miembros del consell y notarios-, y dieron un empuje a su economía. Entre otras cosas erigieron cuatro molinos en el barranco ${ }^{3}$.

Las Ordenanzas para el riego de las Huertas Mayores o de Santa María de la Villa de Ibi reflejan cómo el siete de junio de 1587 se celebró un contrato entre el Consejo General de la Universidad de Ibi y "Els hereters del horta machor de dita Universitat y señors del aigua de aquella", según el cual se obligaron, dichos hereters, a ceder el agua necesaria para el abastecimiento de la Universidad. Hay varios proyectos principales de excavación de alcavones para la mejora del caudal de la Fuente de Santa María. Uno fue descrito por Cavanilles a finales del siglo XVIII y ya entonces sugería la conveniencia de excavar a mayor profundidad (Cavanilles, 1795-1797, II: 182.).

El primer proyecto a gran escala se concluyó en 1889. Consistió en una galería o alcavón de 853,60 metros con once pozos de ventilación a lo largo de su recorrido, que salía a la superficie en el Pantanet de Corbí. Discurría entonces por una acequia hasta un depósito de empalme con filtro y, finalmente, caía al barranco en el lugar conocido como La Cascada. El proyecto estuvo a cargo del ingeniero Emilio Colomina Raduán de Alcoy, y del arquitecto Luis Santonja Faus. En poco tiempo se adoptó la decisión de construir una tubería de hierro y un depósito de aguas potables que se concluyó en 1892. En el pueblo se erigieron tres fuentes monumentales: una en el Carrer Les Eres, que fue trasladada a la Glorieta de España, la de la plaza de la Iglesia, y la de la plaza de la Constitución, hoy de la Palla.

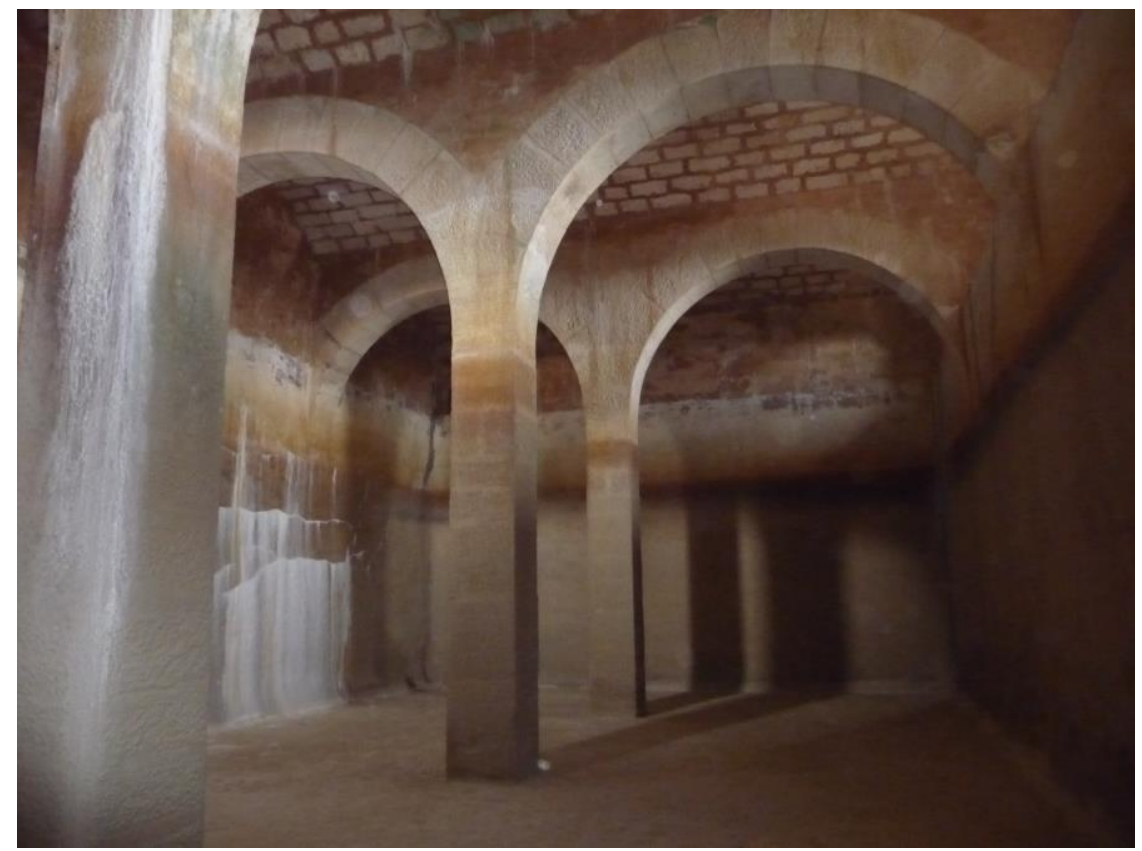

Fig. 3. Depósito de aguas potables construido en 1892.

${ }^{3}$ ARV, MR., 3405, 3406; Espinalt, 1988 [1786], III: 23; Castelló Candela, 2001. 
En 1969 se terminó el segundo proyecto de mejora. El autor fue Juan P. Alcaraz Pavía, y el ingeniero encargado de las obras Diego Irles Pérez. Se excavó un segundo alcavón a mayor profundidad. La galería medía 1.140 metros, tenía diez pozos de registro y discurría hasta un depósito partidor y decantador. El pozo más profundo alcanzaba más de setenta metros de altura. Posteriormente se realizaron diversas ampliaciones y canalizaciones modernas, pero la estructura primigenia se mantiene ${ }^{4}$.

\subsection{Riego de las Huertas Mayores o de Santa María}

Las Ordenanzas para el riego de las Huertas Mayores o de Santa María de la Villa de Ibi se aprobaron en 1879. El caudal de las fuentes estaba destinado a riego de la huerta, abastecimiento de la población y a mover los molinos. En las mismas se establecen las tandas de riego que inicialmente eran de 34 días subdivididos en 816 horas, pero, con el objeto de evitar los inconvenientes del riego a plazo muy dilatado, se redujeron a 17 días, de manera que los propietarios recibían la mitad de las horas de agua en cada tanda nueva. Posteriormente se redujeron a 12 días, y hoy son semanales. La propiedad de las aguas era independiente de la del suelo. Cada día de riego se contaba desde las seis de la tarde hasta la misma hora del día siguiente. Las doce primeras horas del día de riego el agua se recogía en la balsa. Los propietarios de esas horas las utilizaban en las seis horas siguientes regando a hila doble.

Desde la salida del alcavón más moderno, el de 1969, discurre una acequia que va tallada en la roca, a tramos al aire y a tramos en túnel. En la entrada del barranco está situado el partidor del Pont, a partir del cual comienza la derivación de los brazales y la distribución para el riego. Los brazales son: Horta del Pont, Brazal Mayor, Brazal del Lavadero, Secanet y Brazal de la Granja o de San Miguel. Posteriormente a principios del siglo XX se derivó el Brazal de Campos desde el molí Nou. Los barrancos se salvan mediante varios acueductos con arcos de medio punto fabricados de mampostería y algunos rematados con ladrillo. Son el de Corbí, el Pont, el del barranco de las Zorras o de les Raboses, y el Teular. El campo regado ocupaba una superficie de un kilómetro cuadrado aproximadamente.

En el barranco hay numerosos tramos de acequias a distintas alturas que tienen facturas distintas ya que responden a varias conducciones de diferentes épocas. Algunas sólo se distinguen por pequeños trechos situados en los bordes o en los lados del camino que lo recorre. La variación del nivel freático y diversas reparaciones provocaron que algunos tramos quedaran obsoletos. Es el caso de la acequia principal, que partía del azud de Corbí hacia el filtro de aguas potables y el molino de la Peña, la cual, aunque está obsoleta, aún mantiene buena parte de las losas. En 1880 el papelero Antonio Martínez se comprometió a indemnizar a los regantes por los daños que producía su molino. Para ello construyó la acequia que va desde la salida de la galería del Riego de Santa María hasta el partidor de las aguas potables, o del Pont. El empresario acordó con el sindicato las condiciones en las que se debía construir mediante una escritura. Así se estableció que la acequia debía ser de piedra sillería "toda de una misma clase y a satisfacción del sindicato". Las piedras del suelo debían ser de noventa y cinco centímetros de ancho y doce de grueso. La acequia debía tener cincuenta y cinco centímetros de luz y los cajeros entre treinta y cuarenta con un ancho de diez centímetros. Las piedras del suelo debían estar unidas a tope y sentadas sobre material

\footnotetext{
${ }^{4}$ Expedientes del Archivo Municipal de Ibi; Cavanilles, 1797, I: 182; García Sanchiz, 1893; Navarro Verdú, 1966, en Anguiz y Cremades, 1981: 73 y ss.; Cremades, en Anguiz y Cremades, 1981: 57; Monleón, 1994; Ramírez Mellado, 2000: 100 y ss.; Marquiegui, 2013, II: 970-979.
} 
mortero de cal y arena y rejuntadas "con cemento romano de primera clase". Las piedras de las barandas o cajeros debían estar machimbradas unas con otras, sujetándose en la colocación a traba junta, o bien todas ellas a tope y "engofadas". Actualmente los tramos que corresponden con la acequia descrita mayoritariamente están trazados con losas grapadas entre sí, y esta construcción se repite en gran parte de la red de acequias de la Huerta Mayor ${ }^{5}$.

El Brazal Mayor llena la Balsa de los Regantes y desde ésta se distribuye el riego de las Huertas Mayores. En su trazado encontramos multitud de elementos asociados como balsas, partidores, saltos y sangradores. Cerca de la balsa hay dos lavaderos principales que se abastecen también del caudal de la acequia del barranco. El más antiguo es el denominado Llavador dels Malalts o Llavador de Baix, que data de 1860. En 1903 se construyó un segundo lavadero, el de Dalt, situado aguas arriba de éste, en las inmediaciones del Molino de Papel. El lavadero de abajo se empleaba para lavar la ropa de los enfermos y evitar así que el agua contaminada afectara al lavadero de los sanos. En 1998 se rehabilitó y se le añadió la cubierta. En la finca de Santa María y abastecido por la Font de Santa Maria de Peiró se localiza un pequeño lavadero de uso particular y hay otro también pequeño en la Font de la Taula Redona ${ }^{6}$.

En la figura 8 hacemos un extracto de los principales elementos que integran el Sistema de Riegos de las Huertas Mayores.

\subsection{Arquitectura preindustrial. Molinos}

Los molinos son las principales construcciones hidráulicas del entorno, y esto ha quedado reflejado en el topónimo que designa al barranco. En Ibi llegó a haber hasta ocho molinos. Siete eran harineros, aunque uno de ellos comenzó siendo un batán, y un molino de papel. Son el molino del Cup o de Petuta, el de la Peña, el del Tendre o de la Tía Roseta, el del Vicari, el molí Nou, el Chiquet, el Molino de Papel y el de la Balsa. Todos ellos eran de cubo salvo el de la Peña y el de Papel, y sólo el último disponía de balsa, que compartía con los regantes mediante turnos.

La presencia de asentamientos en todo el entorno del barranco puede sugerir la hipótesis de la existencia de molinos hidráulicos antiguos, pero lo cierto es que la primera referencia documentada data de mediados de 1343, según una escritura en la cual Pere Bertomeu arrendaba a Dimanacio Dalpays "un moli al lloc de Ibi" . Otra cita de 1393 también mencionaba el molino en una venta de varios lugares, entre los cuales se encontraba Ibi, en la que el comprador Juan Bellvis hablaba de la necesidad de realizar obras "en lo molí del loch de Ibi en cases per els habitadores de cascún dels dits lochs, les quals obres darien gran melloria als dits lochs e a la senyoria d'aquells's.

\footnotetext{
5 A.M.I.; S.R.F.S.M., 6/2, 14/2; AHMJ, PN. de Santonja y Belda, P., Ibi 153, escritura 51. Sesiones de 14/7 de 1879, 28/9 y 5/10 de 1881, 2 y 6/9 de 1882, Libro de actas del SRFSM., 1879-1902, AMI., SRFSM., $2 / 4$ y 14/2; 13/3 de 1880, AMI., SRFSM., 6/2; AHMJ., PN. de Santonja y Belda, Ibi 153, escritura 51. Véase Marquiegui, 2012a.

${ }^{6}$ Barrachina, 1977, en Anguiz y Cremades, 1981: 464; Anguiz y Cremades, 1981: 64; Anguiz, 1984: 77-83; Ramírez Mellado, 2000: 113.

7 Escritura con fecha 27 de julio de 1343, Archivo Municipal de Alcoy, Notario Pere Barberá 1343-1346 (cortesía de Ramón Molina Ferrero).

829 de octubre de 1393, Archivo Municipal de Valencia, llm. g 3-5, fol. 248 v., en Vidal Beltrán, 1974: 247; Domínguez Moltó, 1978: 105, 284-289, 302. Véase Marquiegui, 2012a.
} 


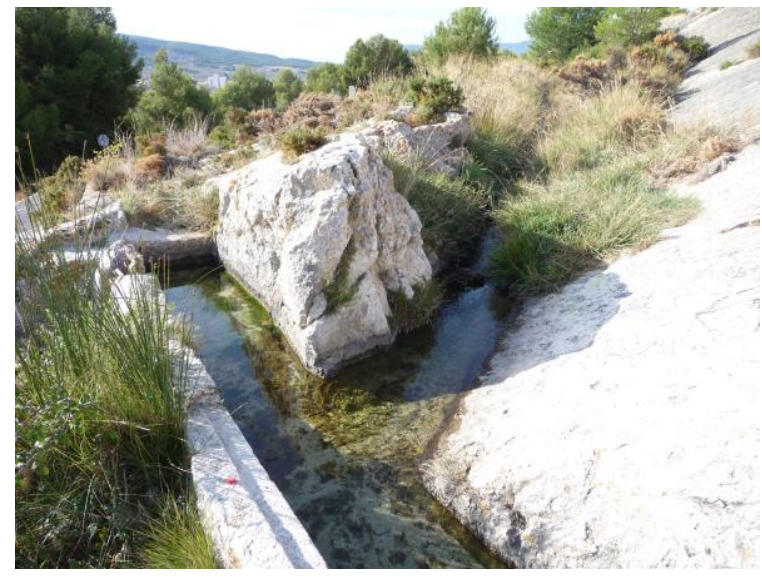

Fig. 4. Partidor del Pont.

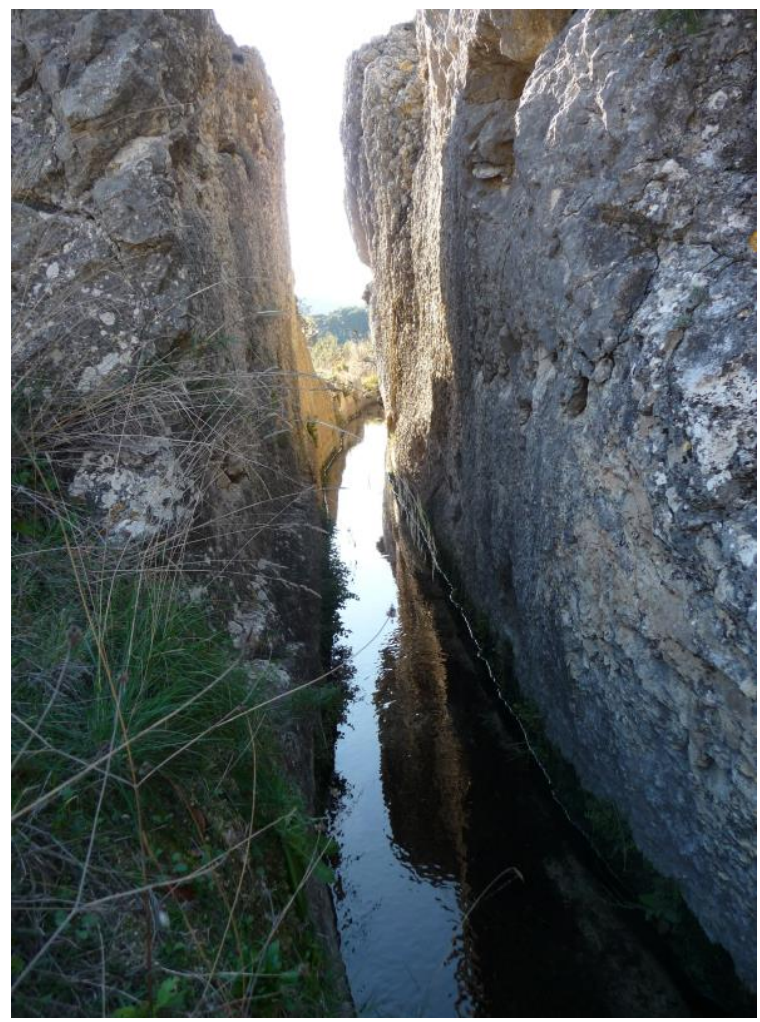

Fig. 5. Acequia del barranco.

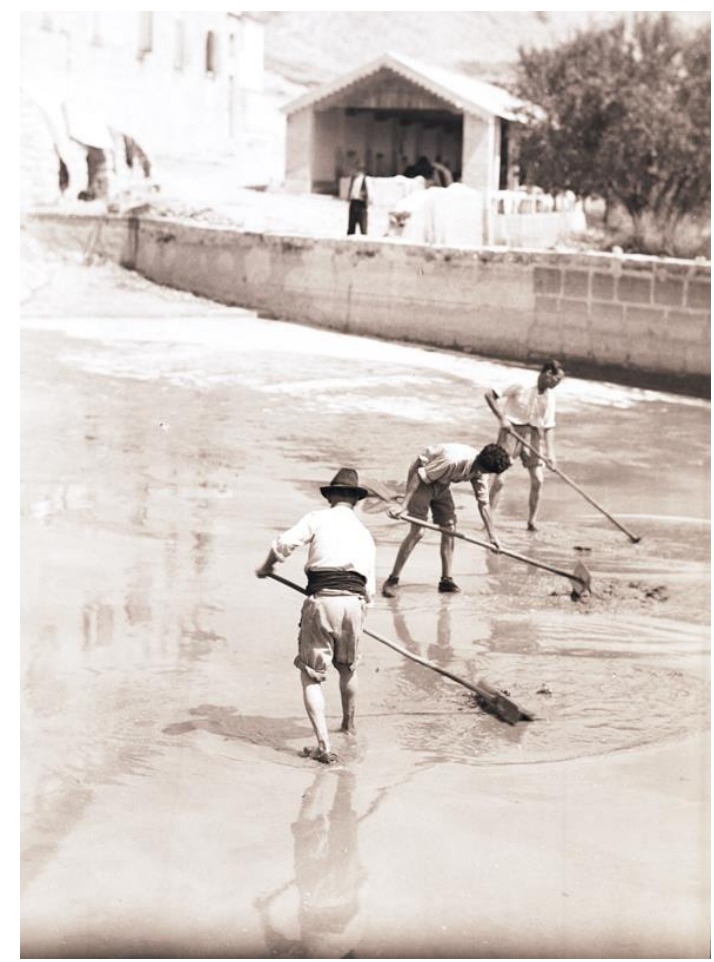

Fig. 6. Limpieza de la Balsa de los Regantes. Fuente: Fondo fotográfico del AMI., Familia Pérez.

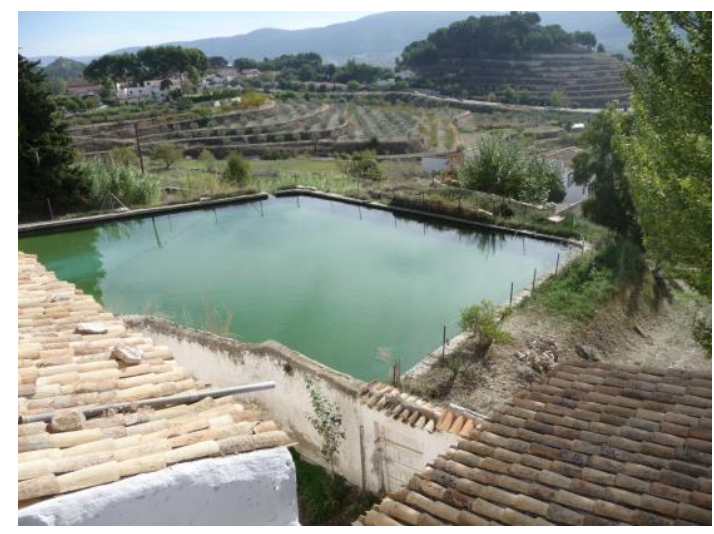

Fig. 7. Balsa de los Regantes vista desde el Secanet. 


\section{Sistema de Riegos de las Huertas Mayores. Principales elementos que lo integran}

\section{Fuentes}

- F-1.- Fuente de Santa María.

- F-2.- Font de Santa María de Peiró.

- F-3.- Font de la Taula Redona.

- F-4.- Font de 1'Horteta Vella, de 1’Horta Vella, o del Lleó.

- F.5.- Font Vella o de Sixto.

- F-6.- Font del Teularet.

- F-7.- Font del Mas de Cantó.

- F-8.- Font del Racó d'Almarra.

- F-9.- Fuente de la Palafanga.

Elementos principales de las conducciones de aguas potables

- Minas y pozos en la fuente de Santa María.

- Acequias de diversas épocas en el barranco.

- CAP-1.- Proyecto de 1797.

- CAP-2.- Proyecto de 1889.

- Alcavón y once pozos

- Depósito de empalme y filtro de aguas potables.

1892.

- Depósito de aguas potables de

- Tres fuentes monumentales en el pueblo.

- CAP-3.- Proyecto de mejora de 1969. alcavón.

- Caseta de acceso al pozo inicial del

- Alcavón y diez pozos.

- Caseta de acceso a la conducción.

\section{Molinos}

- API-1.- Molí del Cup, de Pascual o de Petuta.

- API-2.- Molino de la Peña o dels Corbí.

- API-3.- Molino de la Tía Roseta, del Tendre, del Curt.

- API-4.- Molí del Vicari.

- API-5.- Molí Nou.

- API-6.- Molí Chiquet.

- API-7.- Molino de Papel.

- API-8.- Molino de la Balsa.

\section{Lavaderos}

- L-1.- Llavador de Dalt de 1903.

- L.2.- Llavador dels Malalts de 1860.

- L.3.- Lavadero de Santa María.

- L.4.- Lavadero de la Font de la Taula Redona.
Balsas

- B-1.- Balsa de los Regantes.

- B-2.- Balsa del Secanet.

- B-3.- Balsa de Fernoveta

- B-4.- Balsa junto a los lavaderos.

- B-5.- Balsas Brazal de la Granja.

- B-6.- Balsa Brazal Mayor.

- B-7.- Balsa acueducto del Teular.

- B-8.- Balsa Horta del Pont.

- B-9.- Balsas pequeñas en la Horta del Pont.

- B-10.- Balsa circular depósito.

- B-11- Balsa Acequia de Campos .

\section{Acueductos}

- A-1.- Acueducto de Corbí.

- A-2.- Acueducto Molino de la Tía Roseta.

- A-3.- Acueducto Molí Nou.

- A-4.- Acueducto del Pont. El Brazal del Puente o de la Horta del Pont.

- A-5.- Acueducto del Barranco de las Zorras. El Brazal del Puente o de l'Horta del Pont.

- A-6.- Acueducto del Teular. Brazal del Lavadero.

\section{Azudes}

- AZ-1.- Azud de Corbí

- AZ-2.- Azud de la entrada del barranco, Pantanet del Despartidor.

\section{Acequias y brazales}

- Acequias en el barranco de los Molinos.

- Partidor del Pont o del Puente.

- - Brazal Mayor.

- Brazal de la Granja o de San Miguel.

- Brazal del Lavadero.

- Brazal del Secanet.

- Brazal de l’Horta del Pont o del Puente.

- - Brazal de Campos.

- Acequia de desagüe de Santa María (fuera del entorno)

- Elementos integrados en el Entorno paisajístico del Barranco de los Molinos.

- Elementos integrados en el Entorno paisajístico de las Huertas Mayores 


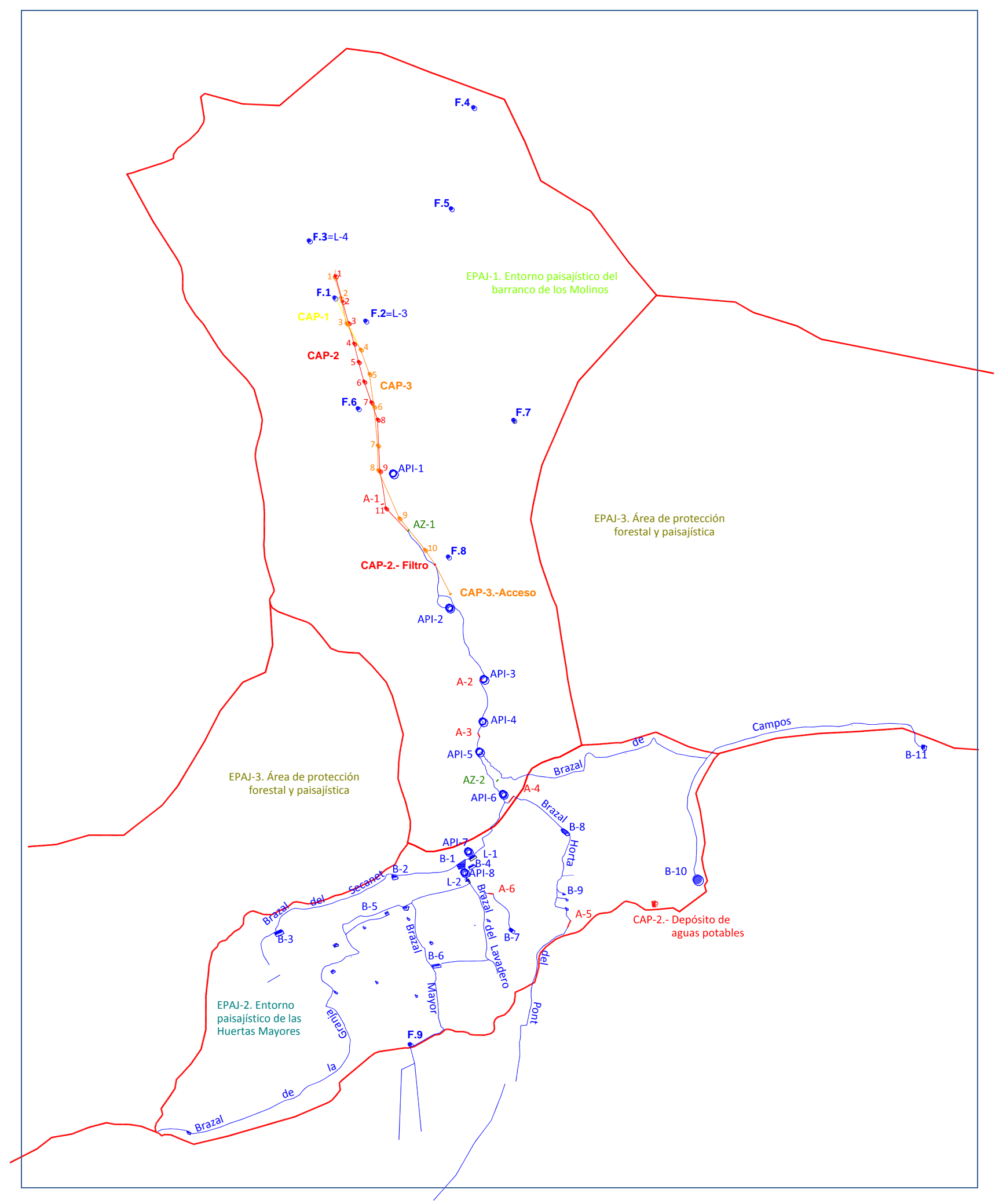

Fig. 8. Sistema de Riegos de las Huertas Mayores. Principales elementos que lo integran 
En 1507 había un solo molino, que probablemente coincidiera con el mencionado, y que, según se deduce de los legajos del Maestre Racional del Archivo del Reino de Valencia, se trataba del conocido como Molino de la Balsa, que entonces se describía como junto al camí de Bocayrent. En 1511 Bertomeu Corbí construyó el primer molino del barranco: el molino de la Peña. Se trata de un caso excepcional ya que el sistema hidráulico de azud y acequia se derivaba hacia una imponente rampa subterránea tallada en la roca ${ }^{10}$. Entre 1533 y 1536 se erigieron otros cuatro molinos en el barranco. El del Cup, el de la Tía Roseta, que comenzó siendo un moli draper, el del Vicari y el Chiquet. Los establecieron los exiliados de Jijona que se asentaron en Ibi huyendo de su lugar de origen por la derrota en la Guerra de las Germanías, como ya hemos comentado ${ }^{11}$.

Los molinos fueron siempre propiedad de particulares y con frecuencia se arrendaban. Normalmente los plazos eran de tres o cuatro años y el precio que se convenía en dinero o en especie. La transmisión era mediante venta o herencia y por eso era común la división del molino entre varios dueños o herederos. Hasta principios del siglo XIX funcionaron seis molinos en total. Todos ellos pagaban un censo de siete sueldos al rey.

En 1830 se estableció el molí Nou y en 1859 se inició la construcción del molino de Papel, que comenzó a funcionar en 1860. Estuvo explotado por varios arrendatarios provenientes de las poblaciones papeleras cercanas de Bañeres y Alcoy, y desde 1868 lo regentó Antonio Martínez Martínez, hasta su fallecimiento en 1888. En 1880 el molino tenía ocho tinas, tres pilas, dos cilindros, cuatro martinetes y una máquina de vapor de seis caballos. Se comercializaron libritos de papel de fumar con las marcas "El Carpintero", "El Martillo" y "La Espada". En 1891 se compraron dos marcas más: "La Esfera" y "El Morso", y en 1902 "La Puerta de Alcalá en Madrid". El industrial fue el autor de la reconstrucción de la acequia que discurre por el barranco ${ }^{12}$.

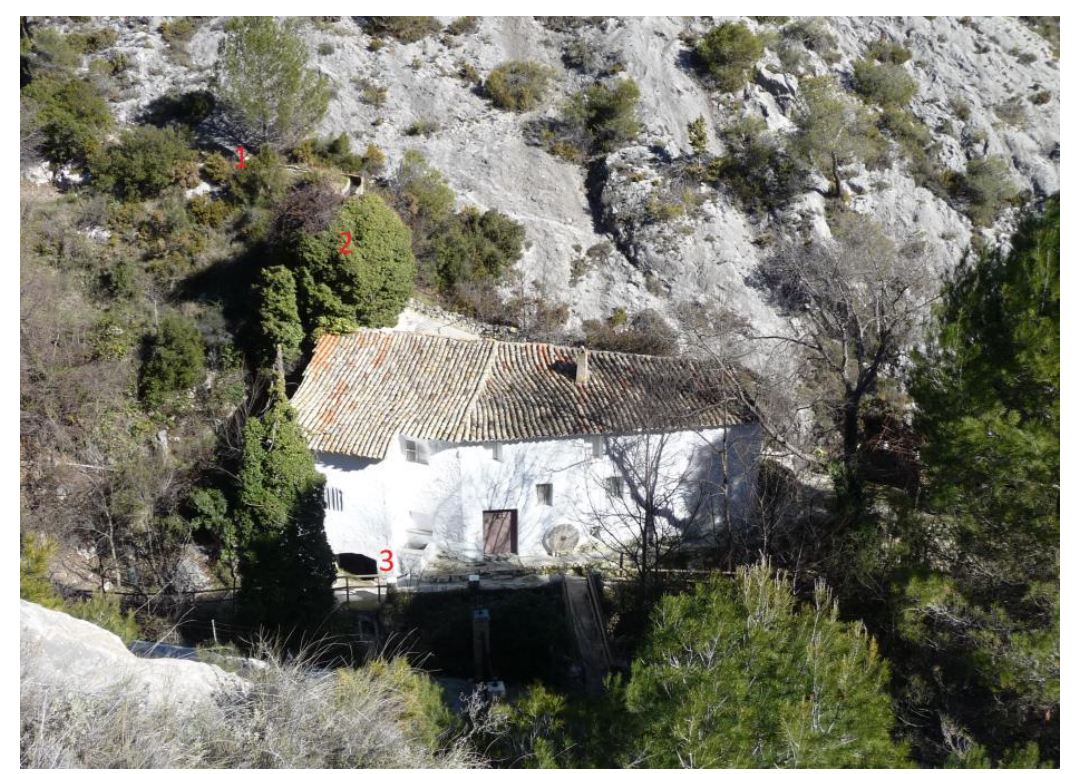

Fig. 9. Molino del Tendre o de la Tía Roseta. 1. Acequia; 2. Cubo o cup; 3. Cárcavo o cacau.

\footnotetext{
${ }_{9}$ Archivo del Reino de Valencia, Maestre Racional, 3384 y ss.

10 ARV., MR., 3388. Marquiegui, 2013a.

${ }^{11}$ Castelló Candela, 2001. ARV., MR., 3405, 3406 y ss.

12 Martínez Tribaldos, 2008; Castelló, 2008; Véase Marquiegui 2012a y 2013, II: 987.
} 


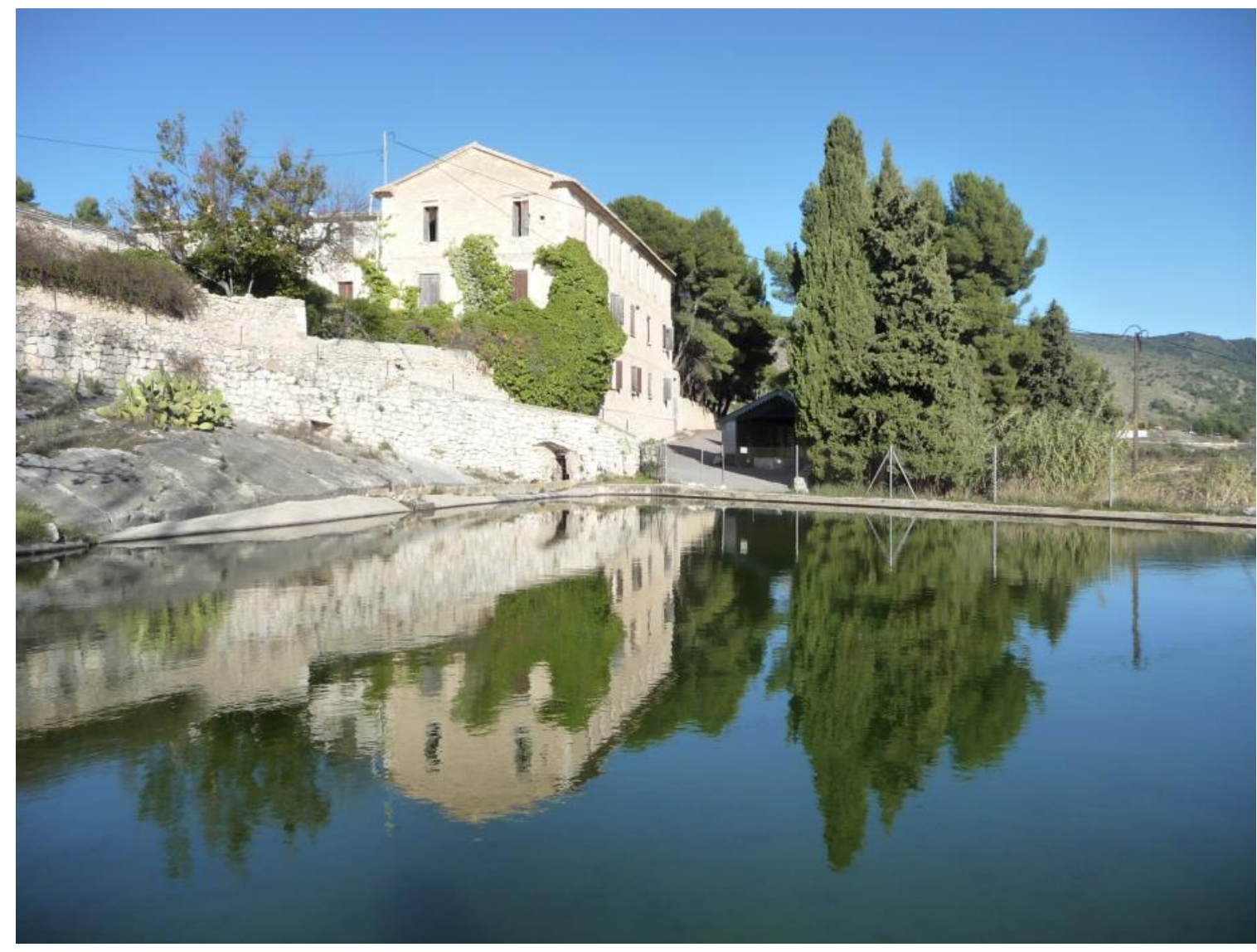

Fig. 10. Conjunto formado por la Balsa de los Regantes, el lavadero y el Molino de Papel.

Según las Ordenanzas para el Riego de 1879, dentro de las tandas de riego a los molinos les tocaban 55 horas, que se repartían de la siguiente manera: Molino de la Peña, nueve horas; Molino del Tendre, siete horas; Molino del Vicari, doce horas; Molino Nuevo, tres horas; Molino de Papel, doce horas; Molino de la Balsa, doce horas ${ }^{13}$. Los molinos dejaron de funcionar debido a la escasez de caudal. El primero en pararse fue el del Cup. Quedó obsoleto en 1871 por las obras del alcavón, que hicieron que descendiera el nivel freático (Marquiegui, 2012b). Desde 1917 la comunidad de regantes decidió iniciar la compra de todos los molinos, "ante la insignificancia de los beneficios obtenidos en las operaciones de invierno por los molinos y el mínimo valor de estos, con la capitalísima importancia y grandes riquezas de la cosecha de verano que no se consigue en las huertas si no se cierra la paleta durante el invierno", y ese fue el inicio de la decadencia de los mismos. El molí Nou fue el último en cerrar. Funcionó hasta los años sesenta gracias a que se instaló maquinaria eléctrica ${ }^{14}$.

\section{Arquitectura de la huerta}

El espacio de la huerta se extiende al norte del casco urbano de Ibi y se encuentra presidido por los cerros de las ermitas de Santa Lucía y San Miguel. En ambos lugares se han

13 Ordenanzas para el riego de las Huertas Mayores o de Santa María de la Villa de Ibi, 1879. Repartos del riego, Archivo Municipal de Ibi, Sindicato de Regantes de la Fuente de Santa María, 14/52.

14 AMI., SRFSM., 14/41. Sesiones del 10/4 y 27/8 de 1871, Libro de Acuerdos de 1862-1879; A.M.I.; S.R.F.S.M, 1/4; Sesiones de 18/3 y 6/5 de 1917, Libro de actas, 1908-1917, pág. 46-47v., A.M.I., S.R.F.S.M., 1/6; Libro de Actas del SRFSM., 1904-1921, AMI., SRFSM., 2/5; Libro de actas, 1917-1927, A.M.I., S.R.F.S.M., 1/7, 2/1 y 4/4; Sesión de 11/1 de 1931, Libro de actas, 1928-1939, AMI., SRFSM., 1/8 y 2/10. Marquiegui, 2012a. 
localizado restos de construcciones antiguas. En Santa Lucía se situaba el Castell Vermell, de época medieval, el cual se declaró BIC en 2003. La construcción de la ermita es probablemente del siglo XVI. En ella destaca el pórtico de acceso con tres arcos de medio punto, el campanario y la vivienda del ermitaño. La ermita de San Miguel se construyó en la segunda mitad del siglo XVIII. Tiene una traza sencilla con una sola nave cubierta con bóveda de cañón y dispone entre los contrafuertes de seis pequeñas capillas laterales (Martínez Tribaldos, 2002; Candelas, 2004.).

Todo el entorno es eminentemente rural. El modelo edificatorio característico es de edificaciones rurales aisladas destinadas a labores agrícolas y vivienda y vinculadas con los antiguos caminos. Se distinguen dos tipos principales. Por un lado las masías, heredades o masets de arquitectura más compleja, que se sitúan en grandes parcelas, y por otro, las casas rurales sencillas. Entre las masías, destacan principalmente Fernoveta, El Secanet, Horta del Pont, Santa Maria de Peiró, Mas de Santa Maria y Campos de Capellanes. Son construcciones de mayor entidad con varias plantas y algunas disponen de amplios jardines con estanques y fuentes. La mayor parte de las construcciones consta de pequeños volúmenes adosados a un cuerpo principal con cubiertas inclinadas y teja árabe. La estructura de los edificios es por general de muros de mampostería con pilares y vigas de madera y las fachadas están enrasadas con mortero con acabado irregular de colores claros, predominando el blanco y el ocre pálido. Originariamente los materiales de construcción eran extraídos de las inmediaciones. Además, deben mencionarse algunas edificaciones singulares destinadas a diversos usos específicos como el Tiny, donde se elaboraban tintes, y dos fábricas de tejas y ladrillos, denominadas teulares.

\section{Paisaje de la huerta}

El rasgo más característico del paisaje agrícola son los aterrazamientos de cultivo o bancales. Son el resultado de la labor agrícola tradicional y de un proceso de transformación del territorio realizado durante siglos, el cual se ha producido en contextos sociales distintos. El sistema de terrazas consiste en el acondicionamiento de superficies cultivables en laderas mediante muretes de piedra seca, que impiden la pérdida de tierra por el arrastre y la erosión provocada por las lluvias y por la labranza, y permiten la retención e infiltración de las aguas de escorrentía. Los bancales pueden ser de secano o de regadío. En el entorno del barranco los bancales son de secano, mientras que el espacio de las Huertas cuenta con una amplia extensión de bancales de cultivo regados por gravedad mediante una red de acequias y balsas. El cultivo predominante es de olivos, almendros, frutales y productos hortícolas que se extienden en pequeñas huertas. La cercanía del casco antiguo del pueblo de este sistema de gradas y riegos constituye un factor a valorar ya que goza de un especial atractivo paisajístico.

Hasta época reciente ha habido un equilibrio armónico entre el conjunto de viviendas rurales y el paisaje agrario, pero en las últimas décadas han ido proliferando construcciones de chalés que se asientan sobre los antiguos bancales y que se intercalan con las casas agrícolas tradicionales. La construcción de nuevas viviendas con volúmenes desproporcionados y materiales no acordes con la arquitectura tradicional y densidades de ocupación excesivas puede poner en peligro el paisaje huertano primigenio. 


\section{Entornos paisajísticos}

Todos los elementos patrimoniales que hemos estudiado se enmarcan dentro de unos espacios de protección que llamaremos entornos paisajísticos. No es casual que la distribución de los yacimientos arqueológicos de distintas épocas coincida con la cuenca de captación de caudal y con el perímetro de regadío de la huerta. A ello se suma la traza de los caminos históricos y de los azagadores. Las masías estaban directamente relacionadas con los caminos, y las vías pecuarias marcan recorridos históricos e incluso prehistóricos. Las trazas se pueden seguir gracias, entre otros, a los planos topográficos de 1899 del Centro Nacional de Información Geográfica (CNIG).

Los entornos paisajísticos vienen marcados también por las visuales, que son tanto el fondo que acompaña o rodea a una obra o conjunto patrimonial, como el paisaje del que forma parte, en el que se integra o que se ve desde la misma. Es relativamente complejo establecer unos límites excesivamente rígidos ya que varían según el punto de vista desde el que se acomete el lugar. Con todo hemos convenido en distinguir tres áreas o unidades paisajísticas que describimos a continuación.

\subsection{Entorno paisajístico del Barranco de los Molinos}

Es el área situada al norte y que abarca la cabecera del barranco y su cuenca hasta el Pont. Ocupa una superficie aproximada de 2,4 kilómetros cuadrados. Constituye la cuenca receptora del caudal y alberga las fuentes y conducciones Toda el área está regulada por el Plan Rector de uso y Gestión del Parque Natural de la Font Roja en diferentes grados. Predominan las zonas boscosas y arbustivas, que se combinan con algunos perímetros de bancales abandonados o con baja explotación. Los límites del entorno vienen dados por la propia cuenca y por las visuales dominantes que se definen por las crestas y laderas de las elevaciones que lo delimitan.

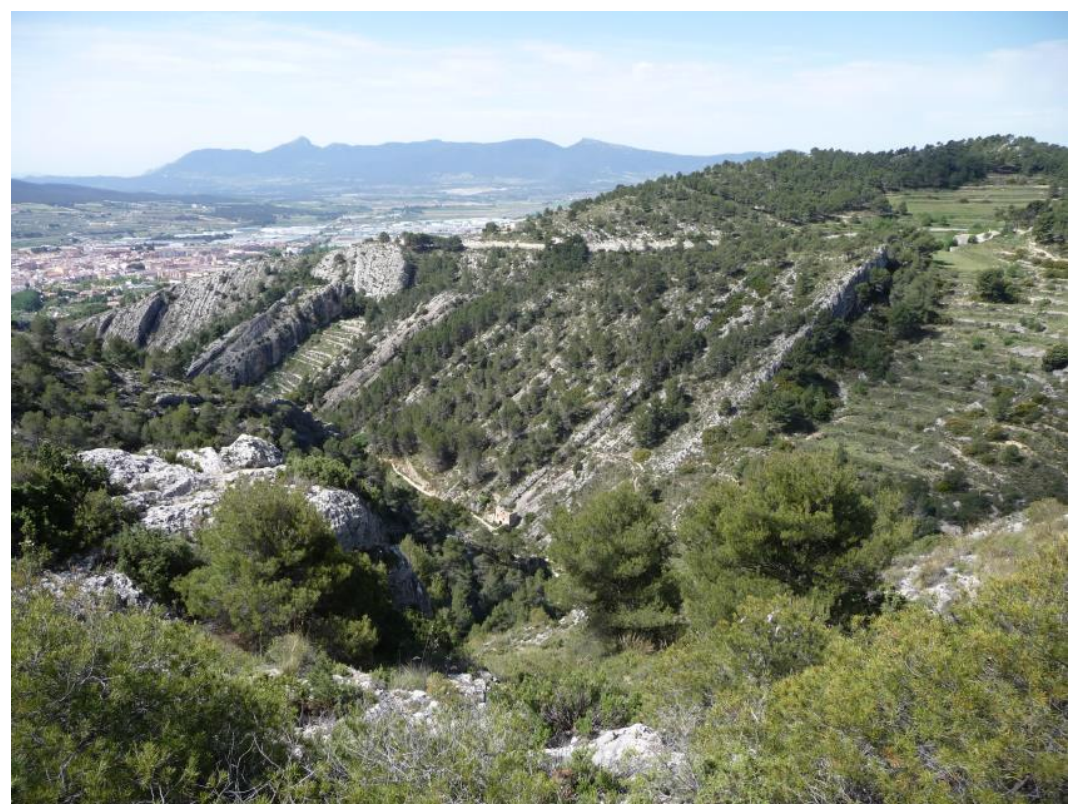

Fig. 11. Entormo paisajístico del barranco de los Molinos. 


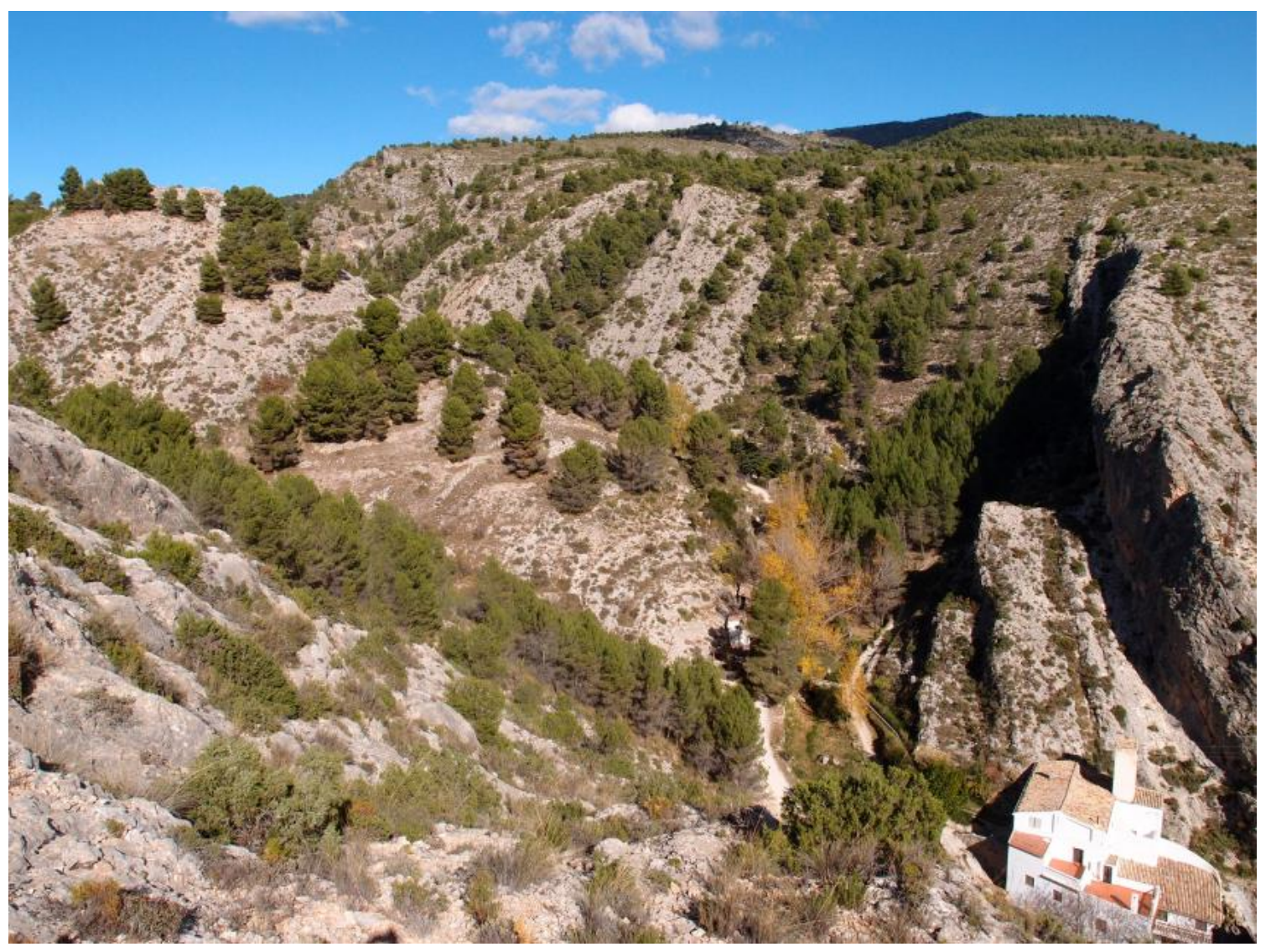

Fig. 12. Tramo bajo del Entorno Paisajístico del Barranco de los Molinos. A la derecha, el Molí Nou, y a la izquierda sobre el cerro los restos del Castell Vell.

\subsection{Entorno paisajístico de las Huertas Mayores}

El espacio comprende toda la zona inferior al Pont desde el cual comienza la división de los brazales del Riego de las Huertas Mayores, que constituye la huerta regada. Está atravesado en su lado este por los barrancos de los Molinos y de las Zorras. Su área es de algo más de un kilómetro cuadrado. Se caracteriza por la extensión de bancales de cultivo regados por acequias, en los que se localizan algunas construcciones agrícolas, viviendas de baja densidad y masías. Las visuales están definidas hacia el norte por las lomas y bosques del Parque Natural de la Font Roja y hacia el sur por el perfil del casco urbano de Ibi, presidido por la cúpula de su iglesia parroquial. El oeste se limita por las elevaciones de la Serra Grossa que se prolongan hacia el sur y suroeste, y por el este con el Altet de Campos. Dentro del espacio de la huerta destacan tres hitos fundamentales situados sobre tres cerros que se elevan en el paisaje. Son las dos ermitas de Santa Lucía y de San Miguel, y la Horta del Pont. 


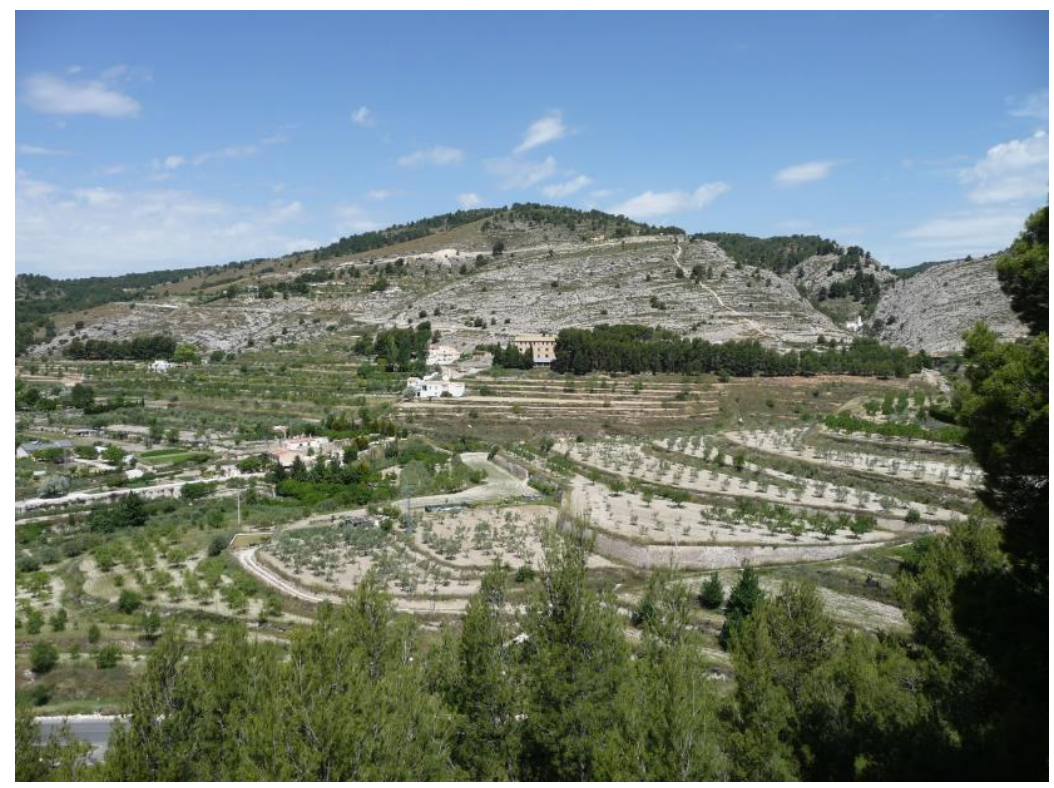

Fig. 13. Sector del Entorno paisajístico de las Huertas Mayores visto desde el cerro de Santa Lucía. En el centro, el Molino de Papel.

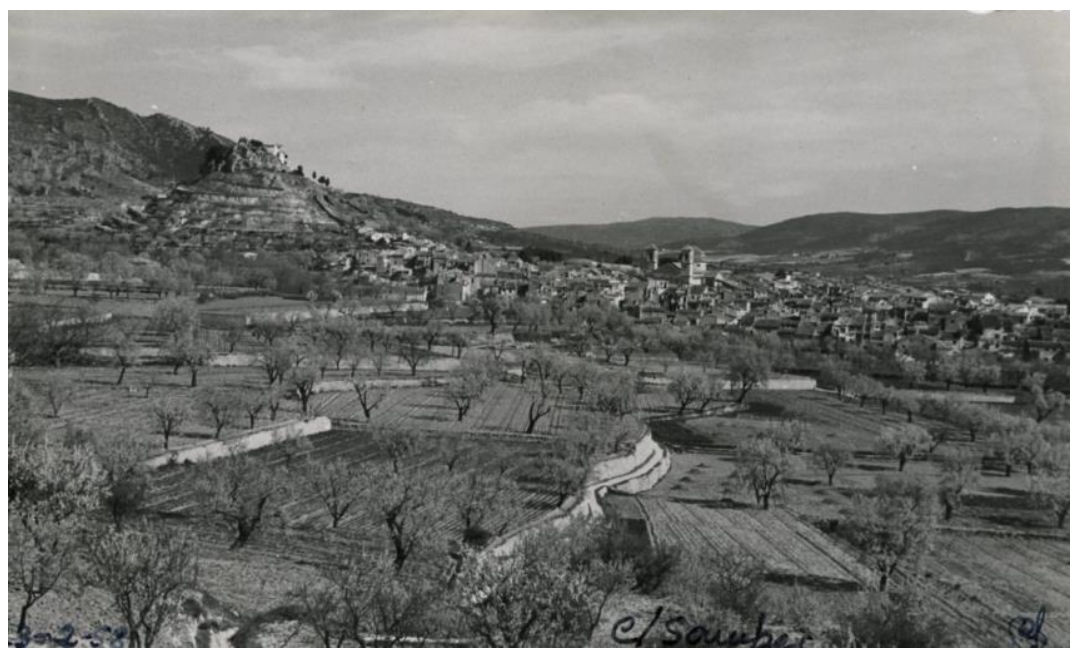

Fig. 14. Vista de las Huertas Mayores desde el cerro de la ermita de San Miguel en 1958. Fuente: Fondo fotográfico del Archivo Municipal de Ibi, Ramón Samper.

\section{3 Área de protección forestal y paisajística}

Es una zona extensa que rodea y actúa como telón de fondo o campo visual de prolongación del espacio regado de las Huertas Mayores y, por añadidura, del perfil del pueblo, y que se adosa al área del Parque Natural de la Font Roja y la amplía. Sus límites se adoptan uniendo las crestas de las sierras y los puntos más destacados del relieve circundante. Por el oeste son la Serra Grossa, Fernoveta Alta y el Cabezo Redó. El norte y noreste están definidos por el relieve de la Sierra del Menejador, con algunos cerros que destacan como el Castell Vell, que preside la entrada del Barranco de los Molinos, el Cabezo 
Guillén o el Alt del Canyo, y por el sur está el casco urbano, que se extiende hacia a Hoya de Castalla. Se caracteriza por ser eminentemente montañosa y forestal.

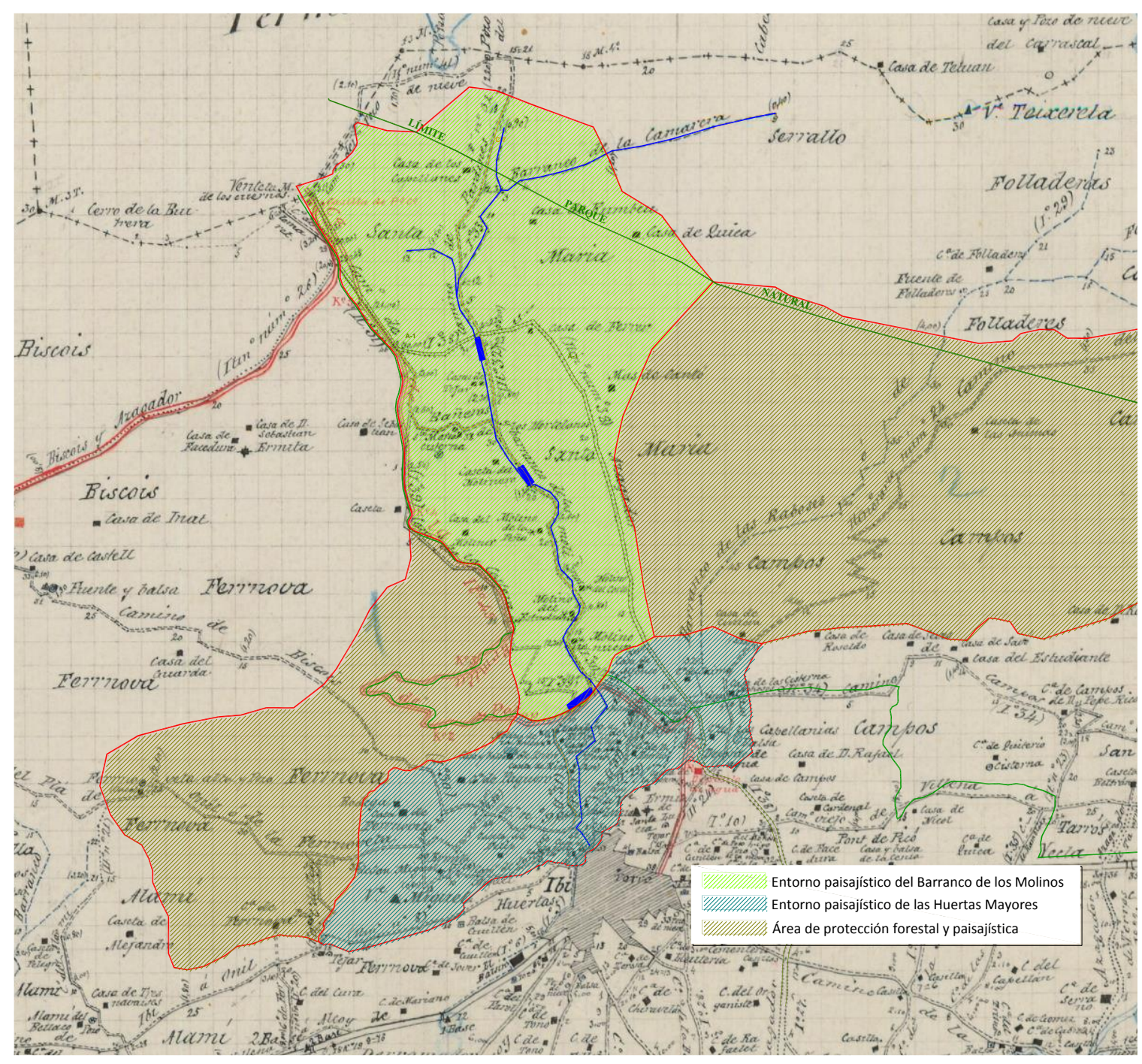

Fig. 15. Mapa de los entornos paisajísticos. Se ha dibujado sobre el topográfico de 1899 del CNIG en el que se trazan los caminos históricos y los azagadores. En azul, los antiguos abrevaderos.

\section{Conclusiones}

La protección de los espacios etnológicos y del patrimonio cultural integra diversos factores entre los cuales los paisajes son un elemento esencial. En el Entorno del Barranco de los Molinos y de las Huertas Mayores el agua es el componente que estructura el sistema sobre el que se insertan y se combinan todos los bienes. Los elementos que integran los espacios etnológicos se pueden considerar como obras independientes, pero siempre vinculados a esta configuración. 
La posibilidad de que se emprendan nuevas perforaciones a gran profundidad y de que se permita la proliferación indiscriminada de chalés y construcciones desacordes con la estética tradicional amenaza con secar el manantial y, por tanto, la biodiversidad del barranco y el sentido expreso de las acequias, y con destruir el paisaje de la huerta, que aún mantiene mayoritariamente sus trazas primigenias marcadas por cultivos tradicionales, acequias, sangradores, bancales y muretes.

La catalogación de este patrimonio debería servir para protegerlo, y podría ser un paso fundamental para fomentar su mejor conocimiento con investigaciones y con excavaciones arqueológicas, que es seguro que incrementarán su gran valor paisajístico y cultural.

\section{Referencias}

Aguirre Sorondo, A. (1998): "La propiedad de los molinos en la Alta Edad media", II Jornadas de Molinología, Terrassa (Barcelona), La Pobla de Cérvoles (Lérida), 30 de septiembre, 1, 2, 3 de octubre de 1998, Fundació Pública Institut d'Estudis Ilerdencs de la Diputació de Lleida, Fundación Juanelo Turriano, Museu de la Ciència i de la Tècnica de Catalunya, Terrassa, pp. 9-23.

Anderson, T. (2011): "Un premier bilan sur la production de meules dans la péninsule iberique de la Protohistoire à le période médiévale". Évolution typologique et techinique des meules du Néolithique à l'an mille. Actes des III Rencontres Archeologiques de l'Archéosite gauolis.

Anderson, T., Augustoni, C., Duvauchelle, A., Sereneels, V. y Castella, D. (2003): Des Artisans a La Campagne. Carriere De Meules, Forge et Voie Gallo-Romaines a Chables (FR). Editions Universitaires De Fribourg.

Anguiz Pajarón, A. y Cremades Marco, C. (1981): Del pasado ibense, Obra Cultural de la Caja de Ahorros de Alicante y Murcia, Alcoy, 655 pp.

Anguiz Pajarón, A. (1984): Miscelánea ibense, Publicaciones de la Obra Social y Cultural de la Caja de Ahorros Provincial de Alicante, Alicante, 360 pp.

Azuar Ruiz, R. (1989): Denia Islámica. Arqueología y Poblamiento, Instituto de Cultura "Juan Gil-Albert", Diputación Provincial de Alicante, Alicante, 450 pp.

Bernabeu Rico, J.L. (1984): Los límites simbólicos. Hombres de la Foia de Castalla y el Vall de Xixona, Instituto de Estudios Alicantinos, Diputación Provincial de Alicante, Alicante, 355 pp.

Candelas Orgilés, R. (2004): Las ermitas de la provincia de Alicante. Diputación de Alicante.

Casado Sánchez, Ma . A. (1978): "La Foia de Castalla", en López Gómez, A. y Roselló Verger, V.M. Dirs., Geografía de la provincia de Alicante, Diputación Provincial de Alicante, pp. 477-490.

Castelló Candela, A. (2001): Ibi, de Lloc a Vila Reial, Monografies Temes d’Ibi, Ayuntamiento de Ibi, Archivo Municipal de Ibi, 560 pp.

Castelló Mora, J. (2008): Molinos papeleros del Alto Vinalopó, Asociació Cultural Font Bona, Centre d'Estudis Locals, Bañeres de Mariola, 509 pp. 
Cavanilles, A. J. (1795-1797): Observaciones sobre la Historia Natural, Geografía, Agricultura, Población y Frutos del reyno de Valencia, Madrid, Imp. Real, 2 vols. (ed. facsímil), Valencia, Albatros, 1995, 2 vols.

Cerdà Bordera, F. (1983): "Contribución al estudio arqueológico de la Foia de Castalla (Alicante)", Revista Lvcentum, 2, Alicante, pp. 69-90.

Cerdà Bordera, F. (1994): El II mil.leni a la Foia de Castalla (Alacant). Excavacions arqueològiques a la Foia de la Perera (Castalla). Recerques del Musen d'Alcoia, 3, Alcoi.

Chabás, R. (1985-1995 [1886-1898]): El Archivo. Revista Literaria Semanal, Edición facsímil, Ayuntamiento de Denia, Instituto de Cultura "Juan Gil-Albert", Diputación Provincial de Alicante, Alicante, 7 vols.

Domínguez Moltó, A. (1978): El Señorío de la Baronía de Planes, Gráficas Vidal-Lekua, Alicante, 334 pp.

Espinalt y García, B. (1988 [1786]): Atlante Español, ó Descripción General de todo el Reyno de España, Tomo X, Descripción del Reyno de Valencia, parte III, Institució Valenciana d’Estudis i Investigació, Generalitat Valenciana, Diputación Provincial de Valencia, 3 vols.

Fairén, S. (2001): "Abrigos, simas y graneros. Sobre el uso de las cuevas en la Edad del Bronce en la comarca de l'Alcoià". Recerques del Museu d'Alcoià, 10: 73-82.

Fairén, S. y García, G. (2004): "Consideraciones sobre el poblamiento neolítico en la Foia de Castalla". I Congrés d'estudis de la Foia de Castalla.

García Atiénzar, G. (2007): La neolitización del territorio. El poblamiento neolítico en el área central del Mediterráneo español. Tesis doctoral. Universidad de Alicante.

García Sánchiz, A. (1893): Aguas potables de la villa de Ibi, 1892, Inédito, mecanografiado, Biblioteca Municipal de Ibi.

Gisbert, J.A. (2000): Cerámica califal de Dénia. Universidad de Alicante.

Glick, T. F.; Guinot, E. Y Martínez, L. P. (Eds.) (2000): Els molins bidráulics valencians. Tecnologia, història $i$ context social, Alfons el Magnànim, Diputació de València, Valencia, 508 pp.

Grau, I. y Moratalla, J. (1999): Espacios de control y áreas de transición en la zona central de la Contestania ibérica. Recerques del Museu d'Alcoi, 9: 179-202.

Grau Mira, I. (2002): La organización del territorio en el área central de la Contestania Ibérica. Universidad de Alicante. 352 pp.

Lajara Martínez, J. (2005): "Excavación arqueológica en el yacimiento ibero-romano del Camino de la Ermita de San Miguel", Actuaciones arqueológicas en la provincia de Alicante.

Lajara Martínez, J. (2006): "El yacimiento del Camino de la Ermita de San Miguel y las evidencias del poblamiento ibero-romano en el término de Ibi (Alicante)", Recerques del Museu d'Alcoi, 15, Museo Arqueológico Municipal de Alcoy, Camil Visedo Moltó, Alcoy, pp. 75-84.

Lajara Martínez, J. (2009a): "La excavación arqueológica de la maqbara de l’Horta del Pont y las evidencias del poblamiento islámico en Ibi", Revista de Moros y Cristianos de Ibi.

Lajara Martínez, J. (2009b): 'La necrópolis islámica de l’Horta del Pont y el poblamiento islámico en Ibi”. Revista de Moros y Cristianos de Ibi.

Lajara Martínez, J. (2010): ‘La necrópolis islámica de l’Horta del Pont, Ibi”. Actuaciones arqueologicas en la provincia de Alicante. 
Lajara Martínez, J. (2011): “Apuntes acerca de los materiales arqueológicos de la colección Dr. Antonio Anguiz Pajarón”. Revista de Moros y Cristianos de Ibi.

Lajara Martínez, J. y Pérez García, A. (2006): "Carta Arqueológica de Ibi”. Actuaciones arqueológicas en la provincia de Alicante 2005 (Edición CD-ROM).

Lajara Martínez, J. y Marquiegui Soloaga, Á. (2014a): "Canteras de molinos manuales en el Barranc dels Molins (Ibi, Alicante)". The 5 th International Colloquium on the archaeology \& geology of Mills and Milling. Museo Arqueológico de Almería.

Legazpi, J. M. (1991): Ingenios de madera, Caja de Ahorros de Asturias, Ministerio de Agricultura, Pesca y Alimentación, IRYDA, Meres (Siero), Principado de Asturias, 137 pp.

Llobregat Conesa, E.A., (1972): Contestania Ibérica. Alicante.

Marquiegui Soloaga, Á. (2012a): "Los molinos hidráulicos en Ibi (Alicante). Catalogación e historia", $8^{\circ}$ Congreso Internacional de Molinología, 28, 29 y 30 de abril de 2012, Tui (Pontevedra), $13 \mathrm{pp}$.

Marquiegui Soloaga, Á. (2012b): "El molino del Cup en Ibi (Alicante)", Revista de Moros y Cristianos de Ibi, pp. 346-348.

Marquiegui Soloaga, Á. (2013a): "Salvemos el molino de la Peña", Revista Molinum, no 45, ACEM, pp. 9-14.

Marquiegui Soloaga, Á. (2013b): El patrimonio bidráulico de la provincia de Alicante. Catálogo ilustrado de mil quinientas obras y actuaciones, Diputación de Alicante, Alicante, 3 tomos.

Marquiegui Sologa, Á. y Lajara Martínez, J. (2014b): Modificación puntual del catálogo de bienes y espacios protegidos. Entorno del barranco de los Molinos, Ayuntamiento de Ibi.

Martínez Tribaldos, M.J. (2002): "La ermita de San Miguel en su 251 aniversario". Revista de fiestas de Moros y Crisitianos de Ibi.

Martínez Tribaldos, Mª J. (2008): "El Molí de Paper de Ibi", Bigneres, Associació Cultural Font Bona, Bañeres de Mariola, pp. 47-52.

Monleón Guillem, M. (1994): "Alcavons del término municipal de Ibi", Revista Moros y Cristianos, Ibi, pp. 209-212.

Palanca, F. (Dir.) (1989): Del gra al pa. El cicle dels cereals, una herba que va canviar la societat, Generalitat Valenciana, Conselleria d'Agricultura i Pesca, Diputació de València, Museu d’Etnologia, Junta d'Obres del Port Autonom, Valencia, 153 pp.

Palomo Palomo, J. (2007): "Molinos hidráulicos: Encuadre histórico", en Garrido, Moreno y Roldán, Eds., Actas del $6^{\circ}$ congreso internacional de molinología, 11 al 13 de octubre 2007, Córdoba, Servicio de Publicaciones de la Universidad de Córdoba, pp. 125-137.

Ramírez Mellado, J. M. (2000): Ibi, una aventura de siglos, Ayuntamiento de Ibi, Diputación Provincial de Alicante, Instituto de Cultura "Juan Gil-Albert", Alicante, 312 pp.

Roca De Togores, C., Gómez, S., Campillo, D. y Lajara, J. (2012): “Tumor epidermoide craneal en un individuo medieval de L' Horta del Pont (Ibi, Alicante). Actas Congreso Nacional de Paleopatología, 2012, Andorra.

Sancho Gisbert, L. y Cortés, M.M. (2011-2012): Revisión de los caminos y azagadores de Ibi entre los siglos XVI y XX, Archivo Municipal de Ibi.

Santos Deltell, M. J. (1987): La Hoya de Castalla, Ayuntamientos de Castalla, Ibi, Onil y Tibi, Caja de Ahorros de Alicante y Murcia, Alcoy, 175 pp. 
Segura, J.M., y Torró, J. (1985): “Torres y Castillos de l'Alcoià-Comtat”, Congrés d'Estudis d'Alcoià-Comtat. Catálogo exposición, Alcoy.

Selma Castell, S. (1993): Els molins d'aigua medievals a Sharq Al-Andalus. Aproximació a través de la documentació escrita dels segles X-XIII (IV-VII H.), Ajuntament d'Onda, 188 pp.

Torró i Abad, J., Nebot i Cerdà, J.R. (2007): "Inter Iui et Alcoy ... Nota sobre una referència de 1251 a la partida de Polop", Iberis 5, pp. 90-95.

Verdú i Guillem, J. (1995): "Retalls de la Nostra Història II. L’Aigua", Revista Moros y Cristianos, Ibi, pp. 154-157.

Vicedo Martínez, M. y Ramírez Gosálvez, J. (2004): Guía de los Pozos de Nieve de la Provincia de Alicante, Excma. Diputación de Alicante, Alicante, 398 pp.

Vidal Beltrán, E. (1974): Valencia en la época de Juan I, Departamento de Historia Medieval, Universidad de Valencia, Valencia, 394 pp.

\section{Fuentes documentales}

AMI. Archivo Municipal de Ibi. SRFSM.- Fondo del Sindicato de Riegos de la Fuente de Santa María. Fondo fotográfico y fondo Municipal.

ARV. Archivo del Reino de Valencia. MR.- Maestre Racional.

ACA. Archivo de la Corona de Aragón.

AHMJ. Archivo Histórico Municipal de Jijona. Protocolos Notariales. 